\title{
Effect of Mechanical Load on Defects Level in Soft Ferrite Ceramics
}

\author{
${\text { A.B. } \text { Petrova }^{1}, \text { A.V. Malyshev }}^{1}$ and A.P. Surzhikov ${ }^{1}$ \\ ${ }^{1}$ Tomsk Polytechnic University, School of High-Energy Physics, 634050 30, Lenin Avenue, Tomsk, Russia
}

\begin{abstract}
The article presents the results of a study of the effect of mechanical load on the temperature dependence of the initial permeability of LiTiZn soft ferrite ceramics. Regimes of mechanical load were created by a steel non-magnetic ring with screws. In this work, four levels of mechanical load were investigated: without load, with 1, 2 and 3 screws. For obtaining temperature dependences and exclude the influence of prehistory on the initial permeability, the samples were heated to a temperature exceeding the Curie point by 50 degrees, after which they slowly cooled to room temperature. The defects level was determined by the ratio of the parameters $\beta / \alpha$ of the phenomenological expression, which describes the experimental temperature dependences. It is shown that as the mechanical load increases, the defects level of ferrite ceramics increases, and after load removing, it returns to its original level.
\end{abstract}

\section{Introduction}

In modern radio electronics, soft ferrites find wide application for manufacturing magnetic amplifiers, inductors, transformer cores, rotors and stators of highfrequency motors $[1,2]$. The most widely used is ferrites synthesized by ceramic technology from a mechanical mixture of oxides or carbonates. The process of ferrites preparation on ceramic technology includes several stages, the purpose of which is the homogenization of the oxide mixture. The advantage of ceramic technology is the low cost and relative simplicity of the technological cycle. However, homogenization techniques used in ceramic technology lead to the appearance of inhomogeneities of a different type, which can have a negative effect on the magnetic characteristics of ferrite [3]. Different methods such as method of measure the true heat capacity, measure the temperature variation of magnetization in the temperature range including the Curie point, and micro$\mathrm{X}$-ray spectral analysis is used for registration defects and evaluation the products homogeneity from soft ferrite ceramics [4]. Studies of the temperature dependences of the magnetic parameters of ferrites are presented in the works $[5,6]$, an analysis of the influence of the ferrite homogeneity on the sharpness of the drop in the temperature curves is made. The disadvantages of these methods are low accuracy, laboriousness, the inability to quantify the changes in chemical composition. For solving these problems, in the Tomsk Polytechnic University is developing a method based on measurements the temperature dependence of the structurally sensitive characteristic of soft ferrites - the initial permeability.
The purpose of this work is approbation the method for evaluating the defects level of ferrite ceramics, based on measuring the temperature dependences of the initial permeability of samples with the mechanical load.

It was expected that an increase of the mechanical load and associated elastic stresses would lead to an increase in the defects level $(\beta / \alpha)$ of ferrite ceramics.

\section{Experimental techniques}

The object of the study is ferrite ceramics, manufactured using classical ceramic technology. Chemical formula: $\mathrm{Li}_{0.649} \mathrm{Fe}_{1.598} \mathrm{Ti}_{0.5} \mathrm{Zn}_{0.2} \mathrm{Mn}_{0.051} \mathrm{Bi}_{0.002} \mathrm{O}_{4}$. The test samples were manufactured by the Ferrit-Domain Co. under production conditions at $\mathrm{T}=960^{\circ} \mathrm{C}, \mathrm{t}=8 \mathrm{~h}$. After sintering, the samples had the toroidal form with an external diameter $\mathrm{D}=20.5 \mathrm{~mm}$, an internal diameter $\mathrm{d}=10.9 \mathrm{~mm}$, a height $\mathrm{h}=3.5 \mathrm{~mm}$.

Samples density and porosity were determined by hydrostatic weighing on an analytical balance Shimadzu AUW 220D.

The grain morphology was studied with a scanning electron microscope Hitachi TM-3000. The average grain size was calculated using the intercept method.

The saturation magnetization (Ms) was measured at room temperature on a magnetometer with a vibrating sample with a maximum field of $0,8 \mathrm{MA} / \mathrm{m}$.

An installation based on an automatic bridge LCR819 and a measuring cell with a built-in heater was built for the measurements. Measuring cell is shown in Figure 1. The measuring cell consists of a stainless steel cylinder (1), which is closed by a fluoroplastic lid (2). A device holding sample (3) and thermocouple (4) is fixed on the lid. Also on the lid, there are holes for the output of conductors (5) from the winding of sample (7). 
Mechanical load is created by a specially designed ring (8) of solid non-magnetic steel with three holes for screws DIN 553. In the lower part of the cylinder there is a pressed copper cup (12), at the bottom of the cup there is a heater (9). The upper part of the cup is covered with an aluminum heat shield (6) to increase the uniformity of heating. All elements are located in an aluminum case (11). The body has connectors that allow connecting the ground wire and the wires that supply the heating element. The body of the measuring cell is thermally insulated with powder of light-weight fireclay bricks 10 .

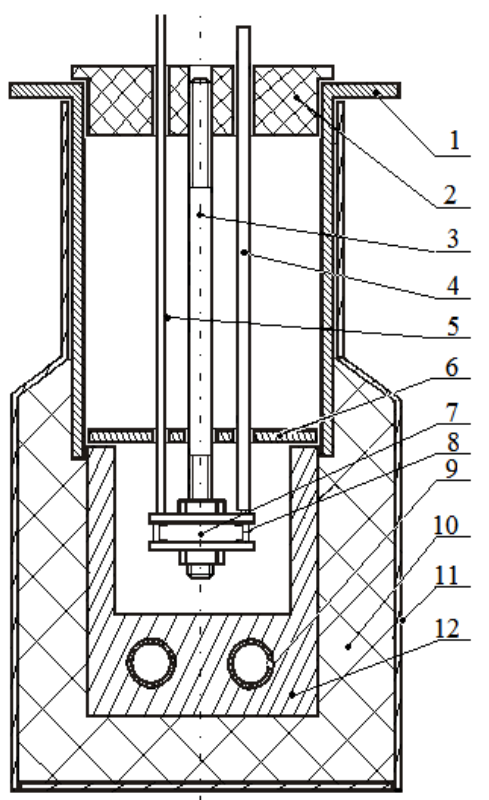

Figure 1. Measuring cell: cylinder (1), fluoroplastic lid (2), device holding sample (3), thermocouple (4), wire outlet (5), heat shield (6), sample (7), steel ring (8), heater (9), fireclay powder (10), aluminum case (11), copper cup (12).

Measurement of the inductance L was carried out on a low-frequency meter LCR-819 in an electromagnetic field with a frequency of $1 \mathrm{kHz}$ with strength of $8 \mathrm{~A} / \mathrm{m}$. Installation is shown in Figure 2.

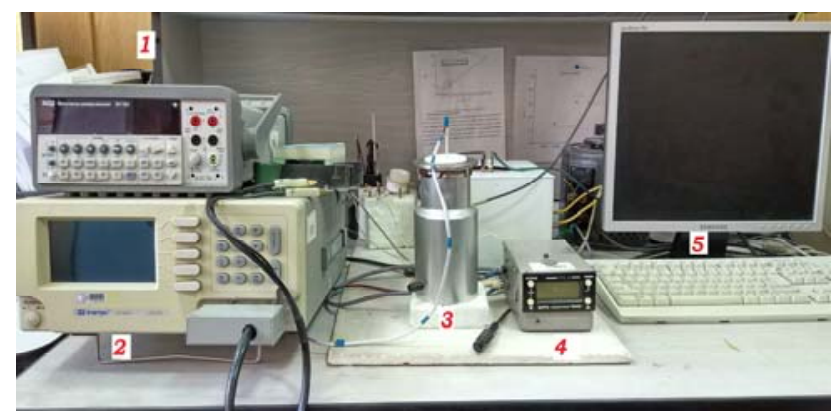

Figure 2.Experimental installationl: 1 - voltmeter, 2 digital meter L, C, R, 3 - measuring cell, 4 - heater, 5 computer.

Ferrite toroid had a single-layer winding. Winding was made of thin copper wire with fluoroplastic insulation.
A non-magnetic steel ring with non-magnetic steel screws was used for creating a mechanical load on sample. Samples were placed into this ring as shown in Figure 3. Mechanical load was created by alternately screwing screws into the sample. Five measurement regimes were chosen: off-load, with one screw, with two screws, with three screws, and after removing the mechanical load.

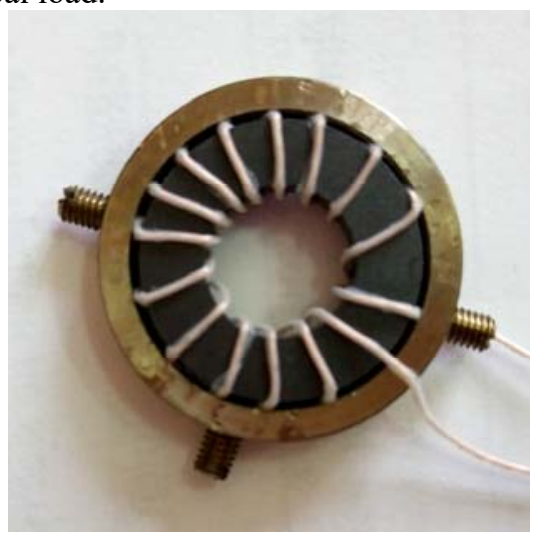

Figure 3. Soft ferrite sample with winding, placed in the steel ring with screws.

The toroidal sample was placed in the measuring cell shown in Figure 1. The sample was measured with a slow cooling of the sample from a temperature 50 degrees above the Curie point using an installation based on an automatic bridge LCR-819 and a voltmeter B7-78 / 1. Temperature control was carried out using a thermocouple of the chromel-alumel group (type K). The measuring junction of the thermocouple was pressed directly to the sample. The inductance data $\mathrm{L}$ from the LCR-819 and the temperature $\mathrm{T}$ were supplied as a text file to the computer using the LabVIEW software package. Calculation of initial permeability values and their mathematical processing took place in the program Origin 9.

The values of the initial permeability were calculated from the formula:

$$
\mu_{i}=\frac{L \cdot 10^{7}}{2 \cdot h \cdot N^{2} \cdot \ln \left(\frac{D}{d}\right)} ;
$$

where L - coil inductance $(\mathrm{H}) ; \mathrm{N}$ - number of coil turns; h - samples height (m); D, d - external and internal diameters of samples (m).

Phenomenological expressions $(2,3)$ were used for the mathematical analysis of the experimental temperature dependences of the initial permeability [7]:

$$
\begin{gathered}
\mu_{i}^{*}=\frac{1+\mathrm{x}}{1+N \cdot \mathrm{x}} \\
x=\left[\frac{\left(1-\frac{T}{T_{c}}\right)^{\delta}}{\alpha\left(1-\frac{T}{T_{c}}\right)^{\gamma}+\beta}\right]
\end{gathered}
$$

In expression (2) the coefficients $\alpha, \beta$, and $\gamma$ are determined by the relations: 


$$
\begin{gathered}
\alpha=\frac{K_{1}(0)}{M_{s}^{r}(0)} \\
\beta=\frac{\lambda_{s}(0)}{M_{s}^{r}(0)} \cdot \sigma \\
\delta=(r-n) f, \\
\gamma=(m-n) f .
\end{gathered}
$$

Where $\sigma$ - the average level of elastic stresses, $N_{f}-$ demagnetization factor, and $g$ and $r$ are specified according to the selected magnetization reversal mechanism [7]. In our work indicators $g, r=2$ was chosen according to the Smith and Wijn model, which is used for polycrystalline ferrites [4].

With positive values of $\gamma$ and $\delta$ functions $(2,3)$ describe an asymmetric peak shape, characteristic for typical dependences $\mu_{\mathrm{i}}(\mathrm{T})$.

The least-squares method (the Levenberg-Marquardt algorithm) of the Origin 9 software was used to process the experimental temperature dependences of initial permeability.

\section{Experimental results}

Figure 4 shows the X-ray diffraction patterns of a ferrite ceramics sample obtained under the sintering regime $\mathrm{T}=960{ }^{\circ} \mathrm{C}, \mathrm{t}=8 \mathrm{~h}$. Also in this figure there are the values corresponding to the diffraction peaks. The X-ray diffraction patterns of the test sample confirmed the formation of a single-phase homogeneous cubic spinel structure.

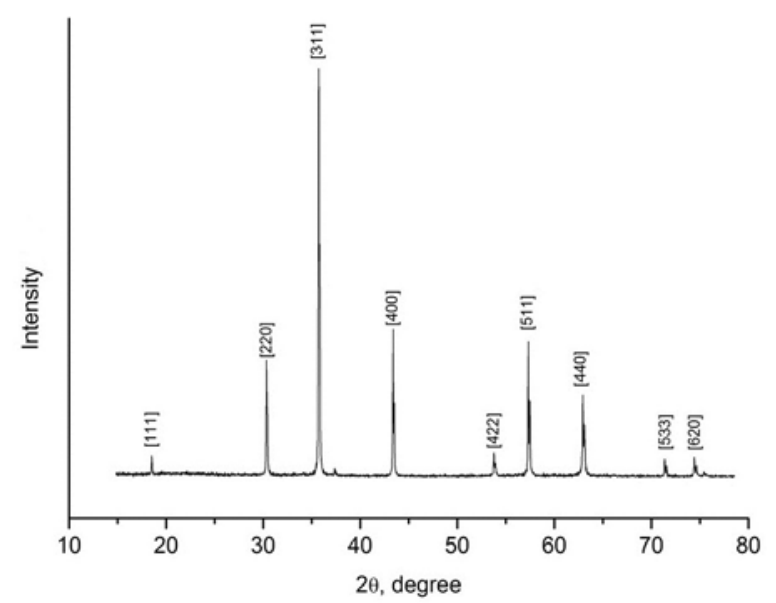

Figure 4. The X-ray diffraction pattern for soft $3 \mathrm{SCH} 18$ ferrite ceramic with sintering regime $\mathrm{T}=960^{\circ} \mathrm{C}, \mathrm{t}=8 \mathrm{~h}$.

A micrograph obtained by scanning electron microscopy on Hitachi TM-3000 is shown in Figure 5.

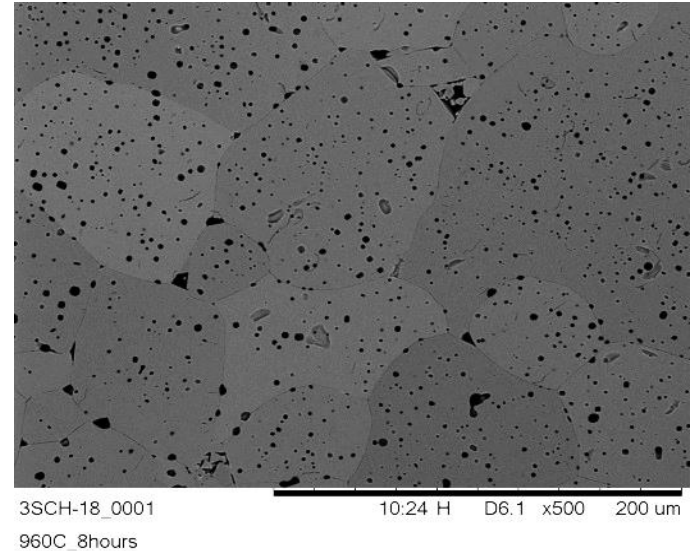

Figure 5. SEM micrograph of soft $3 \mathrm{SCH} 18$ ferrite ceramic with sintering regime $\mathrm{T}=960^{\circ} \mathrm{C}, \mathrm{t}=8 \mathrm{~h}$.

Figure 5 presents that the investigated ceramics is characterized by a polycrystalline structure with wellformed grains.

Table 1 presents the average grain size, density, and porosity of soft ferrite ceramics $3 \mathrm{CH} 18$.

Table 1. Parameters of soft $3 \mathrm{SCH} 18$ ferrite ceramic with sintering regime $\mathrm{T}=960^{\circ} \mathrm{C}, \mathrm{t}=8 \mathrm{~h}$.

\begin{tabular}{|c|c|c|c|}
\hline $\begin{array}{c}\text { Average grain } \\
\text { size }(\mu \mathrm{m})\end{array}$ & $\begin{array}{c}\text { Density } \\
\left(\mathrm{g} / \mathrm{cm}^{3}\right)\end{array}$ & Porosity $(\%)$ & $\mathrm{M}_{\mathrm{s}}(\mathrm{G})$ \\
\hline 47,2 & 4,3 & 4,4 & 1930 \\
\hline
\end{tabular}

As can be seen from Table 1, in spite of the large grain size, the test ferrite has a high density, which reaches $96 \%$ of the X-ray density for this material and a sufficiently low porosity.

The temperature dependences of the initial permeability soft ferrite ceramics samples with different mechanical load regimes are shown in Figure 6.

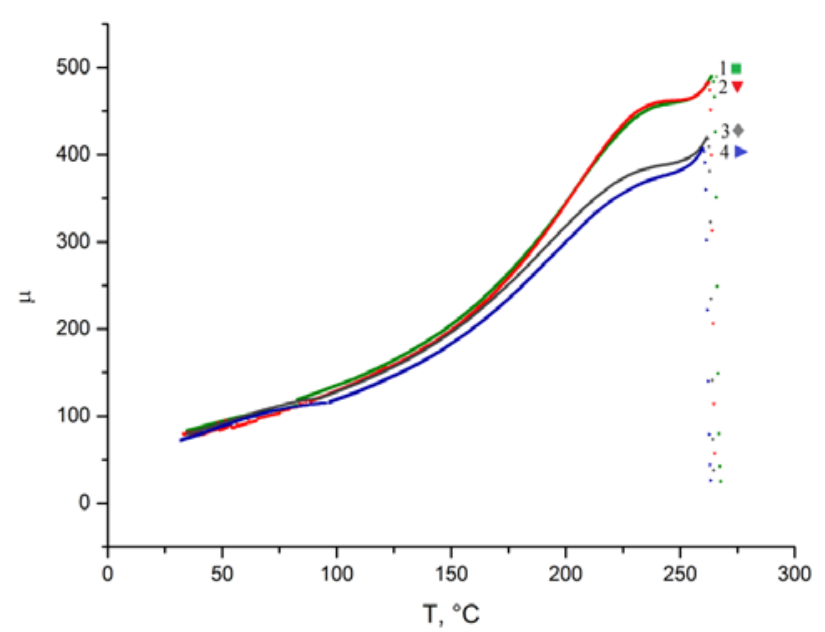

Figure 6. The temperature dependences of the initial permeability soft ferrite ceramics samples with different mechanical load regimes: 1 - off-load; 2 - with 1 screw; 3 - with 2 screws; 4 - with 3 screws. 
As can be seen from Figure 6 the initial permeability near the Curie point for all ferrite samples has the sharp decrease. As shown in the works $[5,6,8]$, this behavior of the curve is characteristic of the single-phase, the chemically homogeneous structure of ferrite ceramics. Thus, the test soft ferrite ceramic has good homogeneity.

The obtained temperature dependences are characterized by two stages of growth. The first stage is characterized by a gradual increase in the initial permeability from room temperature to $250{ }^{\circ} \mathrm{C}$. The second stage is characterized by the Hopkinson peak, which is a sharp increase with the pass of an acute maximum and a sharp fall in the values of the initial permeability near the Curie point. This behavior is associated with the domains transition to a superparamagnetic state, which is inherent in the singledomain state in the case when the domain size and the average grain size coincide, for example, in the case of a nanoparticle [9-11].

The highest maximum of the dependence of the initial permeability on temperature is characteristic for the sample off-load mechanical load. The value of the maximum of the initial permeability decreases with increasing load on the test sample. Therefore, this parameter can be used to estimate the level of mechanical stress and the associated level of elastic stresses in the material.

Table 2 presents the results of mathematical processing of the temperature dependences of the initial permeability of soft ferrite ceramics samples with different levels of mechanical load using the phenomenological expression (2).

Table 2. Results of mathematical processing

\begin{tabular}{|c|c|c|c|c|c|}
\hline $\begin{array}{c}\text { Mech. } \\
\text { load } \\
\text { regime }\end{array}$ & $\alpha$ & $\beta$ & $\mathrm{N}_{\mathrm{f}}$ & $\mathrm{T}_{\mathrm{c}}$ & $\beta / \alpha$ \\
\hline $\begin{array}{c}\text { Off- } \\
\text { load }\end{array}$ & 0,132 & $6.28 \mathrm{E}-6$ & 0.0020 & 266.32 & $\begin{array}{c}4.8 \mathrm{E}- \\
5\end{array}$ \\
\hline $\begin{array}{c}1 \\
\text { screw }\end{array}$ & 0,120 & $5.47 \mathrm{E}-5$ & 0.0024 & 264.76 & $\begin{array}{c}4.6 \mathrm{E}- \\
4\end{array}$ \\
\hline $\begin{array}{c}2 \\
\text { screws }\end{array}$ & 0,121 & $1.54 \mathrm{E}-5$ & 0.0020 & 265.67 & $\begin{array}{c}1.3 \mathrm{E}- \\
4\end{array}$ \\
\hline $\begin{array}{c}3 \\
\text { screws }\end{array}$ & 0,127 & $1.09 \mathrm{E}-4$ & 0.0026 & 268.78 & $\begin{array}{c}8.6 \mathrm{E}- \\
4\end{array}$ \\
\hline $\begin{array}{c}\text { After a } \\
\text { load }\end{array}$ & 0,123 & $8.19 \mathrm{E}-6$ & 0.0020 & 273.46 & $\begin{array}{c}6.7 \mathrm{E}- \\
5\end{array}$ \\
\hline
\end{tabular}

As can be seen from Table 2, with increasing mechanical load, the parameter $\beta / \alpha$ increases due to the increase in elastic stresses and defects level in the sample. After removing the mechanical load, the $\beta / \alpha$ ratio returned to its original value. The demagnetizing factor $N_{f}$ is similar for all regimes of mechanical load and practically does not change.

\section{Conclusions}

Thus, in this paper, the influence of the mechanical load on the temperature dependences of the initial permeability of ferrite ceramics was investigated.

It is shown that as the mechanical load increases, the structurally sensitive parameter of the phenomenological expression $\beta / \alpha$ increases, which is caused by the growth of elastic stresses and defects level in the sample. After the load is removed, the parameter $\beta / \alpha$ returns to the original level, which indicates that there are no irreversible changes caused by the mechanical load. The maximum of the temperature dependence of initial permeability can be used for estimates of the mechanical load level and the associated elastic stress level in the material.

Thus, in this paper, a method for estimating the defectiveness of soft ferrite ceramics samples subjected to mechanical load was approbated.

\section{Acknowledgments}

The research is funded by The Ministry of Education and Science of the Russian Federation as part of the "Science" Program, Project 3.4937.2017.

The experimental calculations were carried out at Tomsk Polytechnic University within the framework of Tomsk Polytechnic University Competitiveness Enhancement Program Grant.

\section{References}

1. R. Valenzuela, Phys. Res. Inter., 2012, 1-9, (2012).

2. L. Jaswal, B. Singh, Journal of Integrated Science and Technology, 2, 69-71, (2014).

3. B.K. Ostafiychuk, L.S. Kaykan, J.S. Kaykan, B.Y. Deputat, O.V. Shevchuk, Nano. Res. Let., 12, 237, (2017).

4. J Smith, H.P.J. Wijn, Philips Technical Library, Eindhoven, Netherlands, 369, (1959).

5. R. Parvin, A.A. Momin, A.K.M. Akther Hossain, J. Mag. and Magn. Mat., 401, 760-769, (2016).

6. J.S. Ghodake, T.J. Shinde, R.P. Patil, S.B. Patil, S.S. Suryavanshi, J. Mag. and Magn. Mat., 378, 436-439, (2015).

7. A.B. Petrova [et al] IOP Conf. Ser.: Mater. Sci. Eng., 289, 012042, (2018).

8. S. Islam, K.H. Maria, S. Choudhury, M. Hakim, D.K. Saha, Turk. J. Phys, 36, 253-259, (2012).

9. M. Marimuthu, S.K. Krishnaswamy, N. Aparnadevi, C. Venkateswaran, Phys. Status Solidi A., 212, (2015).

10. H. Sözeri, A. Baykal, and B. Ünal, Phys. Status Solidi A., 209, 2002-2013, (2012).

11. Q. Fang, H. Cheng, K. Huang, J. Wang, R. Li, and Y. Jiao, J. Magn. Magn. Mater. 294, 281-286, (2005). 